\title{
Artificial Vision System Using Mobile Devices for Detection of Fusarium Fungus in Corn
}

\author{
Pedro Salazar ${ }^{1}$, Saul Ortiz ${ }^{1}$, Talhia Hernández ${ }^{1}$, Nestor Velasco ${ }^{2}$ \\ ${ }^{1}$ Instituto Tecnológico Superior del Occidente del Estado de Hidalgo, \\ Hidalgo, Mexico \\ ${ }^{2}$ University of Central Florida, \\ USA \\ psalazar@itsoeh.edu.mx, ssoto@itsoeh.edu.mx, talhiah@hotmail.com, \\ nestorvb@gmail.com
}

\begin{abstract}
Artificial vision systems aims at mathematically modeling the visual perception systems of living beings and create programs that will allow the simulation of such capabilities by means of a computer system. The current frameworks that run on mobile devices allow both monochromatic and color image processing. The structure and properties of the 3D world that they try to describe aim at not just geometrical properties but also at properties such as material, light intensity/absorption on surfaces in an automated way. In Mexico, the implementation of such technologies in corn crops is almost nonexistent. However, by developing solutions the beneficial impact would boost the creation of technologies that may be able to detect plagues or diseases in crops. The following work proposes the use of an artificial vision system to identify the fusarium fungus on corn crops by integrating the technology in a smartphone and an implementation of javaCV to identify color patterns in the corn and be able to identify any anomaly.
\end{abstract}

Keywords: OpenCV, computer vision, fusarium, image processing, open source computer vision library.

\section{Introduction}

One of the most demanded agricultural product in Mexico is corn, as depicted in Figure 1. With the use of technology in agriculture, there has been significant beneficial changes, i.e., genetic manipulation of corn to provide the crop improved resistance to pests, worms or any additional threats. 


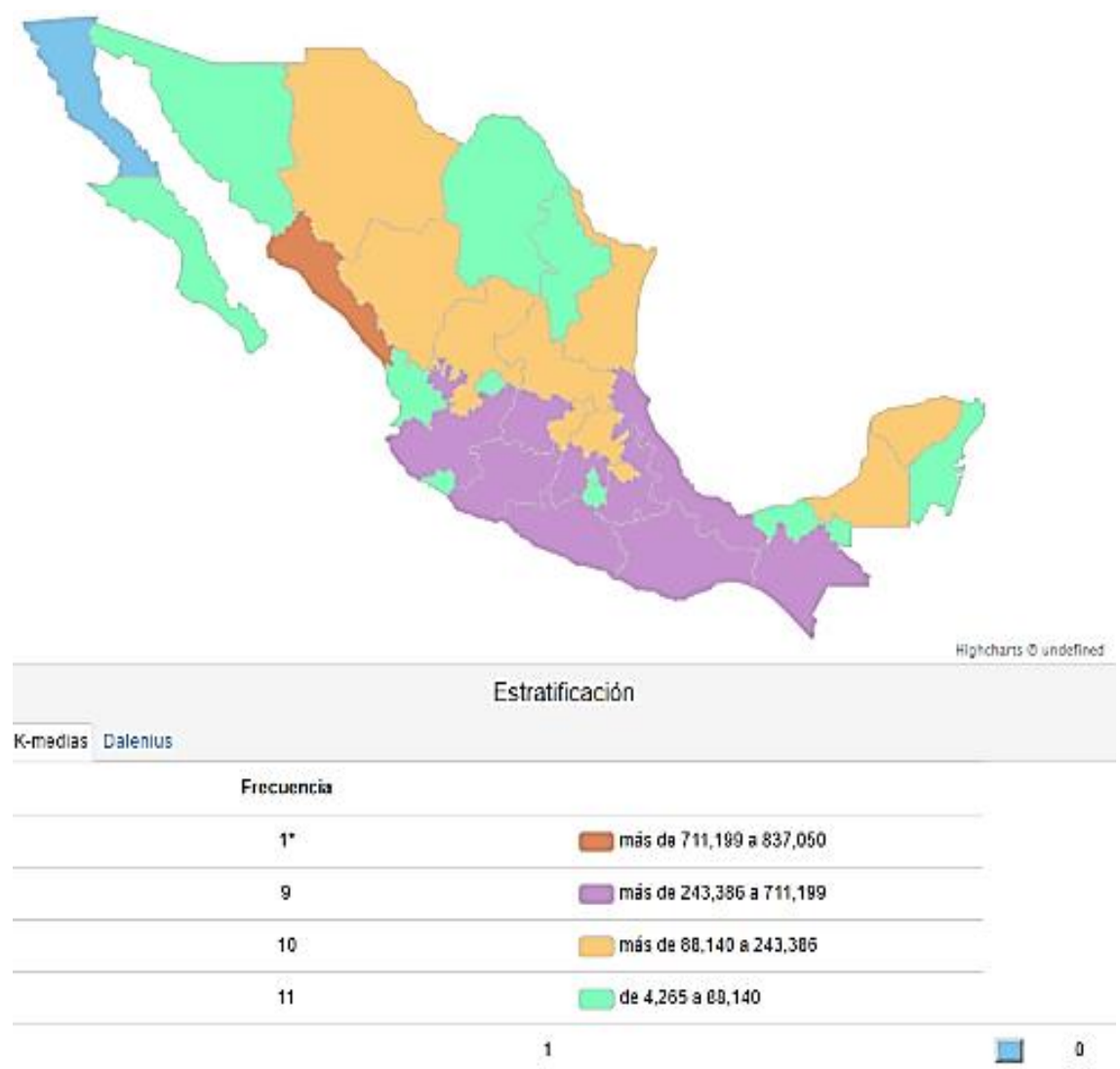

Fig. 1. Corn crops in Mexico [1].

Agricultural technologies in Mexico are often not developed having small producers in mind, due to that, there aren't currently technology based tools that help with the plague detection process. Due to that situation, the proposed work aims at providing a solution based on an artificial vision system for mobile devices that will be able to detect the worst and most common corn fungus: "fusarium". With the use of a mobile device capable of detecting such fungus, common detection errors are avoided, noise factors such as light reflection and noise in color detection are not present.

\section{State of the Art}

There are currently various Computer Vision systems created entirely to agriculture, they are able to recognize not only size, shape, color and texture but assign a numeric value to objects or scenes that are being examined [2]. However, Computer Vision systems dedicated to pest detection are the less [3] but dedicate almost entirely to 
providing advantages and suggestions on how to recollect information related to their current crops [4].

The two most important crops in Mexico are Beans and Corn, currently due to the high internal demand in the country there is a need to import corn and predictions state that given the high demographic growth there will be a need to double the production of such grain.

On the other hand, the irrigation of corn crops can increase substantially its production due to the high performance that can be achieved by duplicating technological tools focused on this grain.

Hidalgo in terms of agricultural land use possess a total of 153.938 hectares dedicated to irrigation; 56.926 of that land were dedicated to corn growth according to the 2007 P.V., 33.450 hectares belong to the Mixquiahuala DDR, where the Mezquital Valley is located.

Mezquital Valley covers 22 municipalities in which corn is produced but irrigated with wastewater, whilst the production potential can be up to 8.1 tons per hectare on average by introducing high yielding genotypes. However, some of them have some susceptibility to some diseases and pests that directly affects the production causing considerable economic losses to producers, the most significant and devastating ones are the smut, rot grain and army worm.

The smut (Sporisorium reilianum) is a fungal disease that affects corn production, destroying the male inflorescence (spike) and female (baby corn) replacing them with a powdery mass of spores [5]. Furthermore, the army worm is considered the most important pest of corn, in recent years it has become common to see it scuttling the stem of the plant to the neck of the root causing its wilting, it drills to the center of the stem and then continues feeding up, damaging the stigmata, the ears, and corn itself.

Due to the economic impact that these diseases and the direct negative effect in net income of producers, the aforementioned figures are an indicator of the risk posed by the smut and army worm and its possible spread throughout the state, and specifically in the Mezquital Valley, this coupled with the fact that this disease is endemic in some regions with geographical and climatic characteristics of the Valley imposes a big challenge.

\section{Description of the problem}

Due to the late detection along with the complications of properly detecting such corn diseases there is a low total production, Table 1 lists the main diseases that affect corn. It's worth mentioning how the fusarium fungus [6] not only attacks corn but also targets fruits such as melon, watermelon and pineapple. This disease causes a $40 \%$ drop of production due to decrease sick plants [7]. Identifying the fusarium fungus is not a simple task, often to make sure that the crop is sick it is necessary to send a sample to a lab to properly identify the type of disease infecting the crop, this traditional approach takes time and in most cases there is no solution to save the crop. 
Table 1. Major corn diseases (pests) [8].

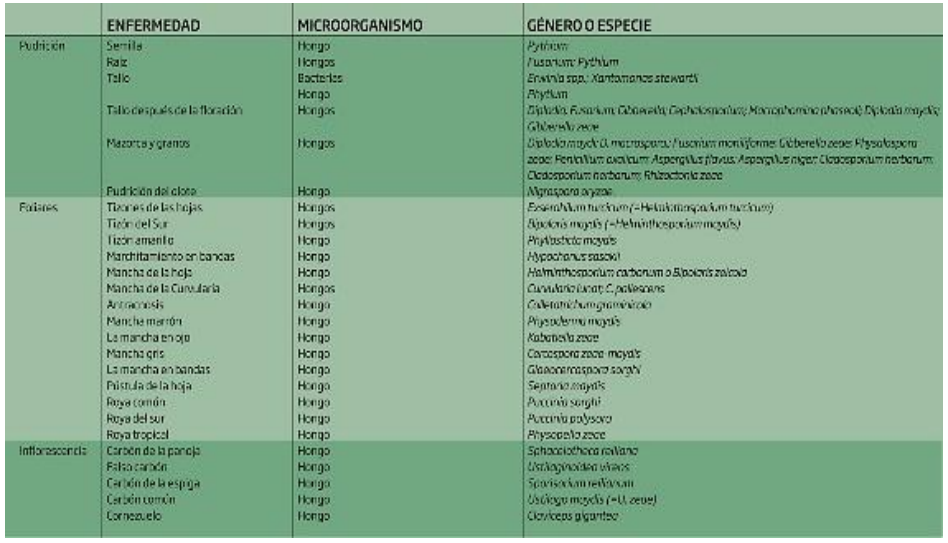

In order to identify the disease in the plant traditionally is done by image processing on a computer, image processing aims to improve the appearance of images and make clear some details that need to be evident, this process can be done by optical or digital methods. In order to perform image processing by means of an artificial vision system there is a need of coupling together digital methods implemented in a computer equipment following a series of steps to carry out the proper processing of in image.

In addition to the resources and methodology that requires image processing, another problem to address is how to train the end user because small farmers lack the knowledge and equipment on the methodology for image processing.

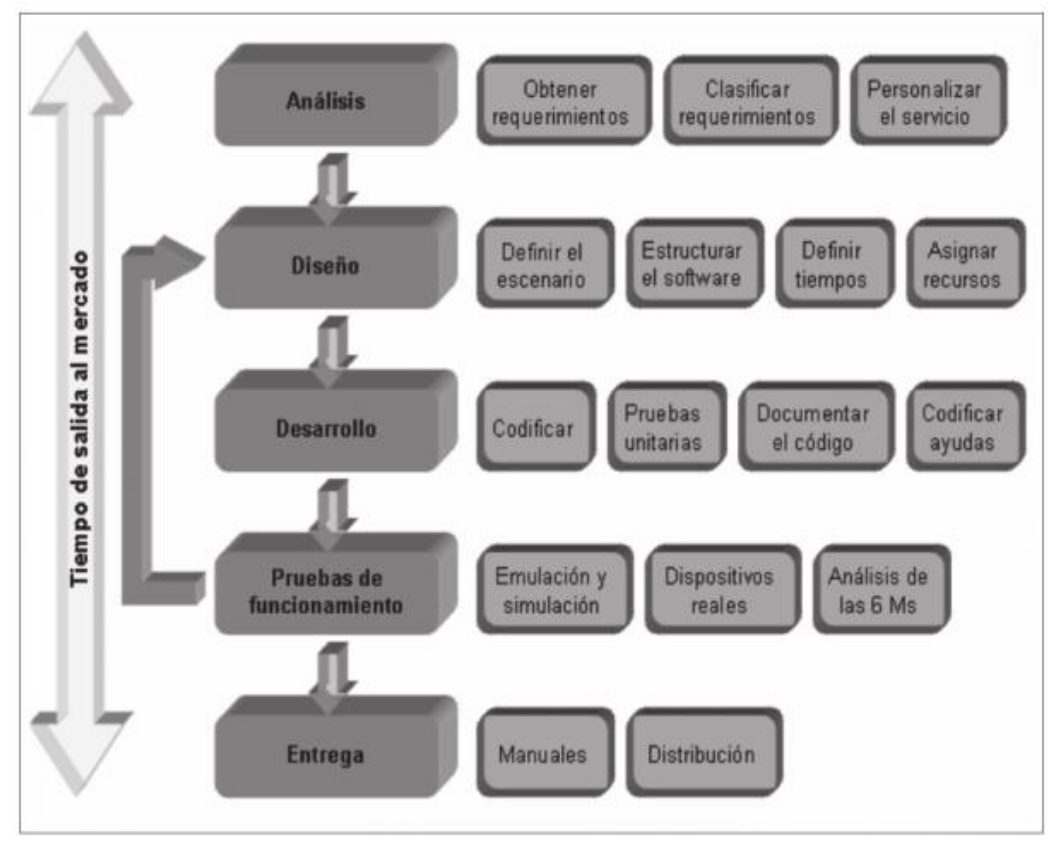

Fig. 2. Stages for mobile application development DrMovil. 


\section{A Mobile Application to Detect the Fungus Fusarium Corn Early}

The methodology used to develop the mobile application is called DrMovil [9]. Figure 2 shows the stages.

\subsection{Analysis}

In this phase the requirements for the development of the mobile application were analyzed, as well as a field research to gather information.

For the field research in the experimental platform where samples of the fungus fusarium corn were obtained, as shown in Figure 3 and that helped define the mobile application should recognize a rectangle by same characteristics of corn stalk.

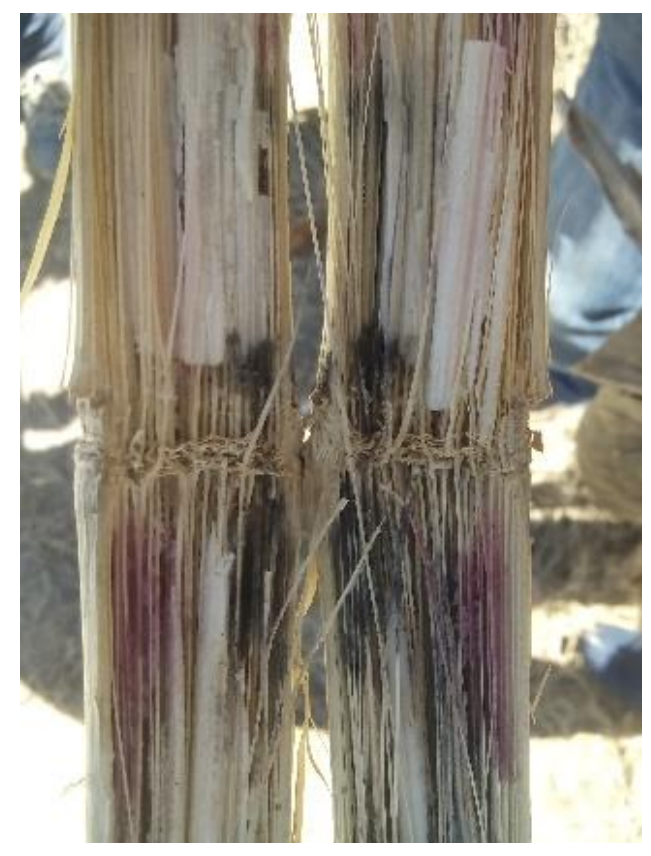

Fig. 3. Fusarium Fungus.

Coloring sick corn stalk is another be considered within the application development. The diseased stem has a particular coloration that by a PAM chemical analysis it's possible to identify the structure and chemical composition of some part of the plant, also when using the method of heat which consists of rising the temperature up to a steam saturation point at a given pressure It is obtained as a result the range of existing colors in the cornstalk, determining whether the fusarium fungus is present. With the support of the Autonomous University of Guadalajara, a study of colorimetry on the sample of the fungus and the results are shown in Figure 4. 

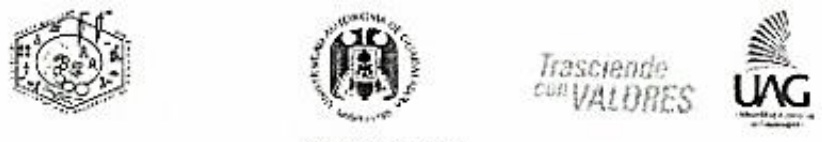

Tatho de Resulutudos

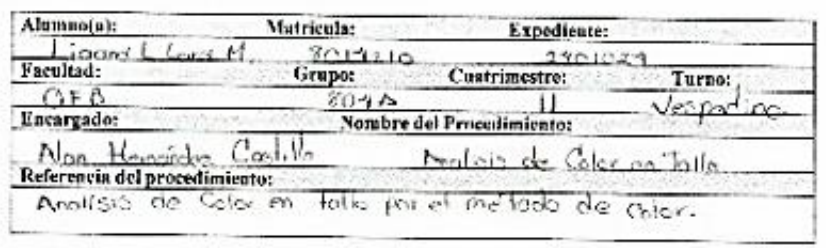

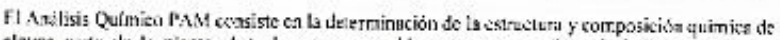

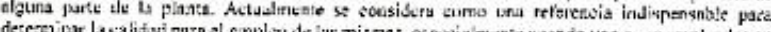

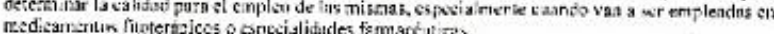
stitedn

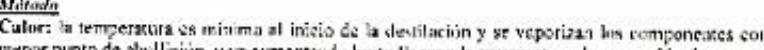

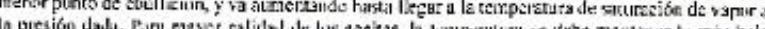
posibie.

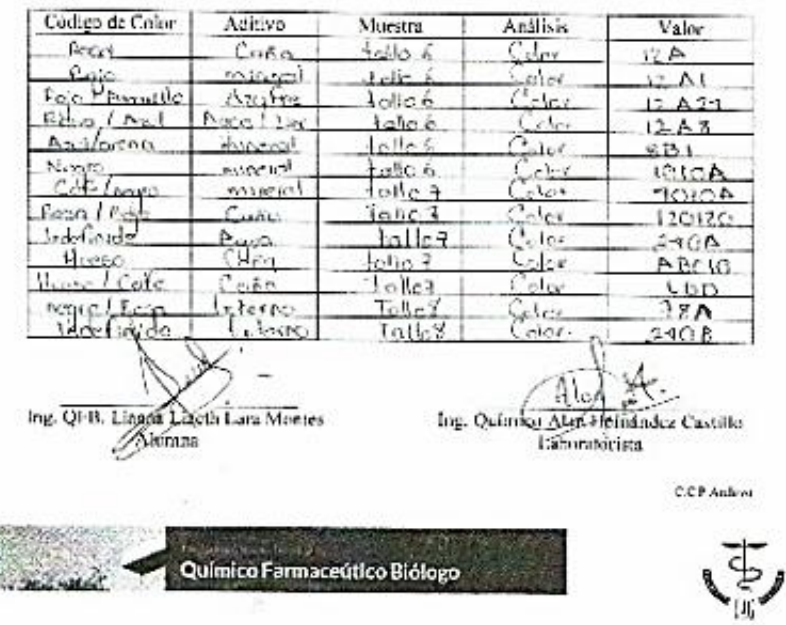

Fig. 4. Results of the color analysis by colorimetry.

To identify the fusarium pest, an OpenCV application was implemented as described by Paul Viola and Michael Jones [10], due to its multiple interoperable capabilities with languages such as $\mathrm{C}++, \mathrm{C}$, Python and Java along with the main operating Systems (Windows, Linux, Mac OS, iOS and Android) [11]. The technique used to detect the fungus is based on simple rectangles detection using a mathematical algorithm based on Haar Wavelets. The waves generated by this algorithm have a square shape per wavelength, to represent such wavelength a pair of adjacent rectangles are used. A light colored rectangle for negative intervals and a dark box for positive intervals (as shown in Figure 5) the formation of this squared wave allowed us to use Haar's features which basically detects the intensity of the pixels identifying the rectangles formed by the Wavelet algorithm of figure 5. 

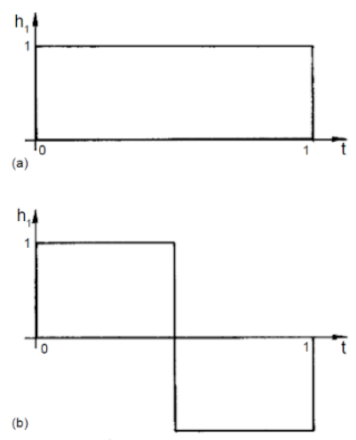

Fig. 5. Haar wavelet: (a) scaling function. (b) mother wavelet [12].

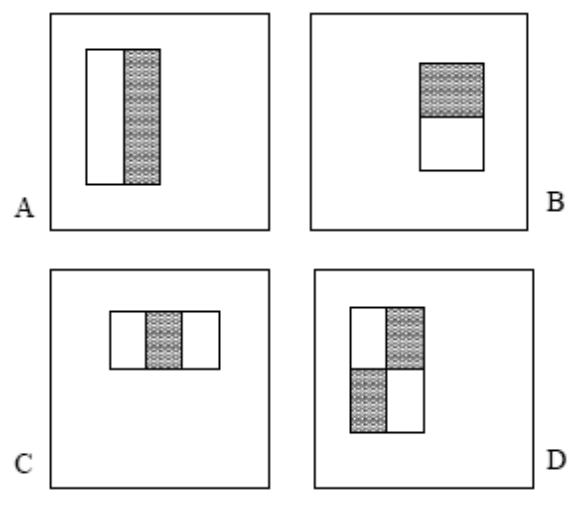

Fig. 6. Haar features [13].

The second feature that was used regarding the learning process is based on AdaBoost along with a combination of a staggered filters (Figure 6). The most intense colors were obtained from the colorimetry test and were used to train the filters that detect the fusarium fungus.

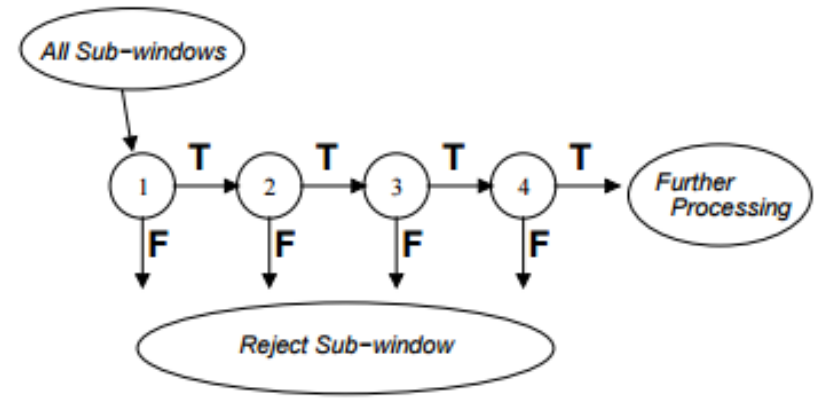

Fig. 7. Cascaded pattern detection. 
The application was tested on a Smartphone with the following characteristics:

- $\quad$ Processor: Qualcomm Snapdragon TM 801 (C) Quad-Core CPUs 2.5GHz

- $\quad$ RAM: 3GB of RAM LP-DDR3

- $\quad$ Camera: 13 megapixels.

\subsection{Design}

The design of the application is intuitive and easy to use, the interface includes options to start the detection process and save the resulting data (Figure 8) (captured photos).

The "help" option contains a detailed description of each of the functions of the application.

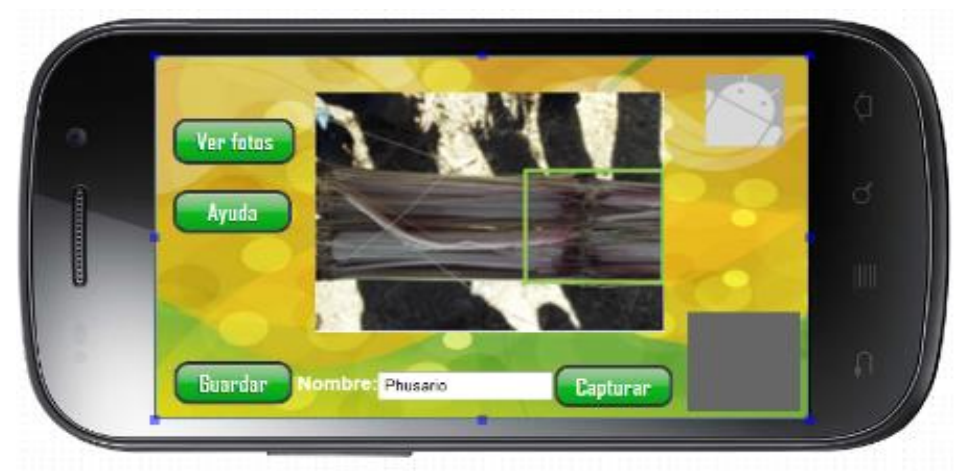

Fig. 8. GUI Design.

\subsection{Development}

The application was created using API Android Studio 16, so it can be installed in any smartphone with Android 4.1 or higher which covers $60 \%$ of current devices on the market. Emulation and simulation tests were performed with the tools provided by Android Studio.

\subsection{Performance Tests}

Performance tests were performed to identify the fungus allocated at the corn stem. The a process is similar to the one implemented by Viola P. \& Jones, M (2001) in which the shapes of the faces are detected, the application detects the shape of cornstalk in $100 \%$ of cases, additional tests were conducted with different plant images to make sure the effective recognition of the corn in a rectangular shape. Complimentary tests were performed using objects with similar shape of a cornstalk and although the shape of a stem was identified, the result was never a positive match for the fusarium fungus as shown in Figures 9 and 10. 


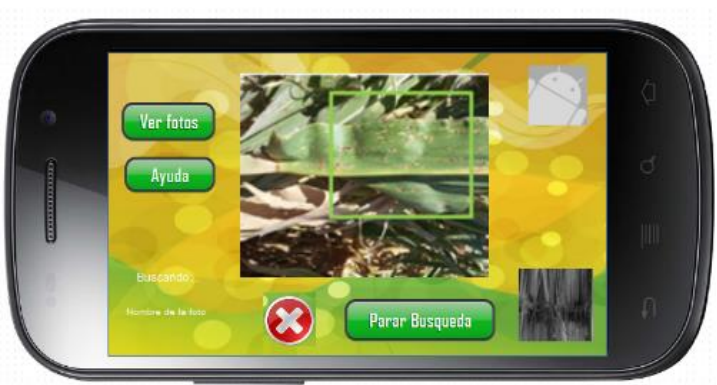

Fig. 9. Application test with another plant.

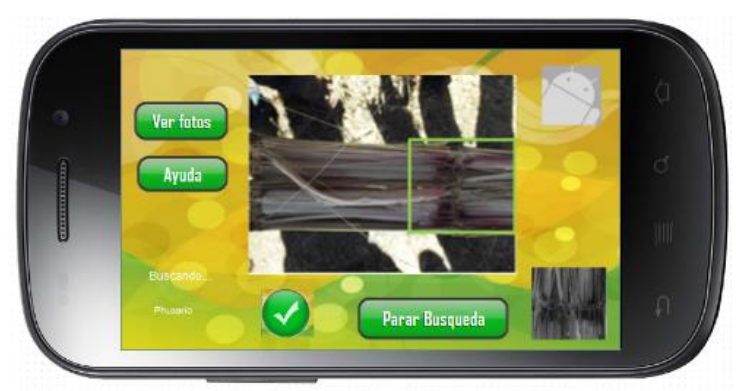

Fig. 10. Recognition test of the fusarium fungus on cornstalk.

\subsection{Current Findings and Future Work}

In this paper the results of the implementation of artificial vision aims at solving an agriculture problem, the intended impact is to provide technological solutions for farmers who do not have the financial resources to cover the needed expenses for studies such as the colorimetry that is needed to determine whether corn is being affected by the fusarium fungus.

As Future work the goal of this work is the creation of a database of diseases like coal spike or army worm that also affects corn. With this catalog the application could not only identify the fusarium fungus but could provide the benefit the possibility of anticipating additional diseases that occur in important crops of agricultural products in the country.

\section{References}

1. SAGARPA, SIAP: Secretaría de Agricultura, Ganadería, Desarrollo Rural, Pesca y Alimentación, Servicio de Información Agroalimentaria y Pesquera (2011)

2. Yud-Ren, C., Kuanglin, C., Moon, S. K.: Machine vision technology for agricultural applications. Computers and Electronics in Agriculture, 36, pp. 173-191 (2002)

3. Camargo, A., Smith, J. S.: Image pattern classification for the identification of disease causing agents in plants. Computers and Electronics in Agriculture, 66, pp. 121-125 (2009) 
4. Lili, N. A., Khalid, F. N., Borham, M.: Classification of herbs plant diseases via hierarchical dynamic artificial neural network after image removal (2011)

5. Bizzocchi, A.: Los Colores y su Significado. Ideas Marketing, Website: http://www.ideas chicago.com/los-colores-y-su-significado (2013).

6. González, I., Arias, Y., Petei, B.: Aspectos Generales De La Interacción Fusarium oxysporum f. sp. lycopersici-tomate. Revista de Protección Vegetal, La Habana, 6 (2012)

7. Quintero, J. A., Apodaca, M. A.: Pudrición de la mazorca. Manejo Sustentable del Maíz. Fundación produce Sinaloa, Sagarpa, Gobierno del estado de Sinaloa, pp. 71-78 (2008)

8. El Maíz En Los Trópicos: Mejoramiento y producción. Fao.org., Retrieved 23 September 2016, from http://www.fao.org/docrep/003/x7650s/x7650s10.htm (2016)

9. Gasca, M., Camargo, L., Medina, B.: Metodología para el desarrollo de aplicaciones móviles. RT, 18(40), pp. 20 (2014)

10. Viola, P. Jones, M.: Robust Real-time Object Detection. Cambridge, Massachusetts, Compaq Computer Corporation, Retrieved from: http://www.hpl.hp.com/techreports /Compaq-DEC/CRL-2001-1.pdf (2001)

11. OpenCV: OpenCV. Opencv.org, retrieved from: http://opencv.org/ (2016)

12. Stankovi'c, R.S., Falkowski, B.J.: The Haar wavelet transform: its status and achievements. Comput Elec Eng., 29, pp. 24-44 (2003)

13. Características de Haar. Universidad Autónoma de Barcelona (2016)

14. Santacruz, V., Santacruz, C., Welti, J., Farrera, R. R., Alamilla, L., Chanona, J., Gutiérrez, G. F.: Effects of air-drying on the shrinkage, surface temperatures and structural features of apples slabs by means of fractal analysis. Revista Mexicana de Ingeniería Química, 7(1), pp. 55-63 (2008)

15. OpenCV: OpenCV, Open Source Computer Vision, Website: http://opencv.org/ (2015)

16. Stack overflow. Learning JavaCV in pure Java, Stack overflow Website: http:// stackoverflow.com/questions/11494546/learning-javacv-in-pure-java (2012)

17. Tlapale, A. D., Chanona, J. J., Mora, R., Farrera, R. R., Gutiérrez, G. F., Calderón, G.: Dough and crumb grain changes during mixing and fermentation and their relation with extension properties and bread quality of yeasted sweet dough. International Journal of Food Science and Technology, 45(3), pp. 530-539 (2010)

18. Lili, N. A., Khalid, F., Borhan, N. M.: Classification of herbs plant diseases via hierarchical dynamic artificial neural network after image removal using kernel regression framework. International Journal on Computer Science and Engineering (IJCSE), 3(1), pp. 15-20 (2011)

19. Unisem: Carbón de la espiga en valle del mezquital: la solución es de todos. Retrieved from: http://semillastodoterreno.com/2013/02/carbon-de-la-espiga-en-valle-delmezquital-la-solucion-es-de-todos (2013)

20. Fundación Hidalgo Produce: Carbón de la espiga del maíz. Retrieved from: http://www. upfim.edu.mx/libro/libros/espigaMaiz.pdf (2014) 